\title{
Energy system contribution in a maximal incremental test: correlations with pacing and overall performance in a $10-k m$ running trial
}

\author{
M.V. Damasceno ${ }^{1}$, L.A. Pasqua ${ }^{1}$, A.E. Lima-Silva ${ }^{2}$ and R. Bertuzzi ${ }^{1}$ \\ ${ }^{1}$ Grupo de Estudos em Desempenho Aeróbio da USP (GEDAE-USP), Departamento de Esporte, \\ Escola de Educação Física e Esporte, Universidade de São Paulo, São Paulo, SP, Brasi \\ ${ }^{2}$ Grupo de Pesquisa sobre Ciência dos Esportes, Centro Acadêmico de Vitória, Universidade Federal de Pernambuco, \\ Vitória de Santo Antão, PE, Brasil
}

\begin{abstract}
This study aimed to verify the association between the contribution of energy systems during an incremental exercise test (IET), pacing, and performance during a 10-km running time trial. Thirteen male recreational runners completed an incremental exercise test on a treadmill to determine the respiratory compensation point $(\mathrm{RCP})$, maximal oxygen uptake $\left(\dot{\mathrm{VO}}_{2 \mathrm{max}}\right)$, peak treadmill speed (PTS), and energy systems contribution; and a 10-km running time trial $(\mathrm{T} 10-\mathrm{km})$ to determine endurance performance. The fractions of the aerobic $\left(\mathrm{W}_{\mathrm{AER}}\right)$ and glycolytic $\left(\mathrm{W}_{\mathrm{GLYCOL}}\right)$ contributions were calculated for each stage based on the oxygen uptake and the oxygen energy equivalents derived by blood lactate accumulation, respectively. Total metabolic demand ( $\mathrm{W}_{\text {TOTAL }}$ ) was the sum of these two energy systems. Endurance performance during the T10-km was moderately correlated with $\mathrm{RCP}, \dot{\mathrm{VO}}_{2} \mathrm{max}$ and PTS $(P<0.05)$, and moderate-to-highly correlated with $W_{A E R}, W_{G L Y C O L}$, and $W_{T O T A L}(P<0.05)$. In addition, $W_{A E R}, W_{G L Y C O L}$, and $W_{\text {TOTAL }}$ were also significantly correlated with running speed in the middle $(P<0.01)$ and final $(P<0.01)$ sections of the T10-km. These findings suggest that the assessment of energy contribution during IET is potentially useful as an alternative variable in the evaluation of endurance runners, especially because of its relationship with specific parts of a long-distance race.
\end{abstract}

Key words: Aerobic metabolism; Running; Maximal oxygen uptake; Anaerobic metabolism; Endurance performance

\section{Introduction}

Traditionally, physiological and mechanical variables, such as maximal oxygen uptake $\left(\dot{\mathrm{V}}_{2 \max }\right)(1)$, metabolic thresholds (2), and peak treadmill speed (3), have been used to measure the performance of long-distance athletes with different training status. $\dot{\mathrm{V}} \mathrm{O}_{2 \text { max }}$ is widely accepted as the upper limit of a body's aerobic functioning (1), which is considered a key component of endurance capacity (4). In turn, running economy, metabolic thresholds, and peak treadmill speed are related to energetic efficiency (5), cellular acidosis (6), and anaerobic metabolism (7), respectively. Therefore, the relationship between these physiological variables and endurance performance appears to owe to the ability to remove metabolites related to fatigue, as well as resynthesizing ATP aerobically and anaerobically. In addition, it was suggested that the distribution of exercise intensity in a race [i.e., pacing) is also a relevant factor for athletic performance (8). Thus, the distribution of exercise intensity can be determined by monitoring physiological responses to avoid premature fatigue and maximize performance (9).
Recent studies have demonstrated that running intensity varies considerably during middle and longdistance events (8) and is associated with the interplay between energy systems. Hettinga et al. (10) found that aerobic metabolism increased until the end of a $4-\mathrm{km}$ cycling time trial, whereas anaerobic metabolism was greatest during the last part of the race. In addition, Nummela et al. (11) found a positive association between the speed of the final lap in a 5-km running time trial and the highest speed measured in a maximal anaerobic running test. Collectively, these findings suggest that the interaction between aerobic and anaerobic metabolism may be decisive in these kinds of events.

The contribution of both metabolisms is important, and an estimation of the contribution of energy systems during exercise can be determined by the energy equivalent of $\mathrm{O}_{2}(12,13)$. Previous studies have used oxygen uptake and oxygen energy equivalents derived by blood lactate accumulation to estimate the contribution of aerobic and glycolytic metabolisms, respectively $(12,14,15)$. More

Correspondence: R. Bertuzzi: <bertuzzi@usp.br>.

Received February 24, 2015. Accepted June 3, 2015. First published online September 18, 2015. 
recently, Bertuzzi et al. (13) used this method to analyze the profile of energy contribution by aerobic and glycolytic systems during an incremental exercise test (IET). These authors demonstrated that the relative aerobic contribution progressively decreased by only $9 \%$ from the first to last stage, suggesting this pathway was predominant throughout the IET. In addition, it was observed that glycolytic metabolism did not contribute largely to the energy expenditure at intensities above the anaerobic threshold. Because the contribution of the energy systems is important for determining variations of exercise intensity and overall performance, it would be interesting to verify whether the energy contribution during an IET could be related to running speed in different sections of an endurance event. This might help coaches and sports scientists to develop specific training programs and understanding pacing strategies for specific events.

Therefore, the purpose of this study was to investigate the relationship between the relative contributions of the aerobic and glycolytic systems, as well as the performance and running speed in different sections of a $10-\mathrm{km}$ running time trial. Based on past studies showing that aerobic metabolism is predominant in events with different distances (16), and increases from the start until the end of cycling time trials (10), whereas anaerobic metabolism is important in the middle and final sections of time trials $(10,17)$, we hypothesized that energy system contribution is correlated to overall performance, aerobic energy system contribution is correlated with speed at different sections of a time trial (start, middle, and end phase) and that glycolytic energy system contribution is strongly correlated with the end phase of a race. Therefore, this would represent an alternative method for assessing endurance runners.

\section{Material and Methods}

\section{Participants}

Thirteen male, recreationally trained long-distance runners (means \pm SD: age: $32.3 \pm 7.5$ years; weight: $68.2 \pm 10.2 \mathrm{~kg}$; height: $173.1 \pm 10.9 \mathrm{~cm}$ ) volunteered to participate in this study. All participants regularly competed in 10-km running races at a regional level. They also had personal records of $40 \pm 5 \mathrm{~min}$ in $10-\mathrm{km}$ running races, had performed at least ten $10-\mathrm{km}$ running races in the last 2 years, and had trained in the last 3 years without interruption. The subjects' running training volume was $38.6 \pm 4.4 \mathrm{~km} /$ week, reported as the mean distances covered, assessed through a training log recorded for 2 weeks prior to the beginning of the study and for the following 2 weeks. The participants received a verbal explanation about the possible benefits, risks, and discomfort associated with the study, and signed a written informed consent before study participation. All subjects were healthy non-smokers with no cardiovascular or neuromuscular diseases. The study was previously approved by the Ethics Committee for Human Studies of the Escola de Educação Física e Esporte, Universidade de São Paulo.

\section{Experimental design}

Each subject visited the university on two separate occasions within a 7-day period, with each session separated by at least $48 \mathrm{~h}$. Each completed: a) an IET to exhaustion on a treadmill for the determination of the respiratory compensation point $(\mathrm{RCP}), \dot{\mathrm{V}} \mathrm{O}_{2 \max }$, peak treadmill speed (PTS) and energy system contributions; and b) a 10-km time trial (T10-km) on an outdoor track to determine overall endurance performance and pacing. The subjects were instructed to refrain from exhaustive or unaccustomed exercises and the ingestion of caffeinated or alcoholic beverages for $24 \mathrm{~h}$ before the tests.

\section{Procedures}

Incremental exercise test. Before starting the IET, participants were asked to rest quietly in a standing position for $5 \mathrm{~min}$ to determine the baseline $\dot{\mathrm{VO}}_{2}\left(\dot{\mathrm{VO}}_{2}\right.$ baseline). After a 5 -min warm-up at $12 \mathrm{~km} / \mathrm{h}$, the test was started with a treadmill speed of $13 \mathrm{~km} / \mathrm{h}$; then the speed was increased by $1 \mathrm{~km} / \mathrm{h}$ every $3 \mathrm{~min}$ until volitional exhaustion. The treadmill (model TK35, CEFISE, Brazil) was set at a gradient of $1 \%$ throughout the IET to simulate outdoor running (18). Subjects received strong verbal encouragement to continue as long as possible. Each stage was separated by a 10-s rest period, during which capillary blood samples $(25 \mu \mathrm{L})$ were obtained from the earlobe and analyzed for blood lactate concentrations (YSI 1500; Yellow Springs Instruments, USA). Breathby-breath pulmonary gas exchange data were collected continuously using a gas analyzer (Metalyzer 3b, Cortex, Germany) and a mean value was determined over consecutive 20 -s periods. Calibration of the device was performed according to manufacturer specifications using ambient air of known composition containing 20.9\% $\mathrm{O}_{2}$ and $5 \% \mathrm{CO}_{2}$, and a $3 \mathrm{~L}$ syringe (Model 5530 Series, Hans Rudolph, USA). Heart rate was measured during the test with a heart rate monitor coupled to the gas analyzer (S810, Polar Electro Oy, Finland). The maximal heart rate was defined as the highest value obtained at the end of the test. The $\dot{\mathrm{VO}}_{2 \text { max }}$ was determined when two or more of the following criteria were met: an increase in $\mathrm{V}_{2}$ of less than $2.1 \mathrm{ml} / \mathrm{kg} / \mathrm{min}$ on two consecutive final stages, a respiratory exchange ratio greater than 1.1 , or a heart rate \pm $10 \mathrm{bpm}$ of the maximal age-predicted heart rate (19). The RCP was determined by three independent investigators as the point of a nonlinear increase in the $\dot{\mathrm{V} E} / \dot{\mathrm{V}} \mathrm{CO}_{2}$, a constant increase in the $\dot{\mathrm{V}} \mathrm{E} / \mathrm{VO}_{2}$, and the first decrease in the expiratory fraction of $\mathrm{CO}_{2}(20)$. The highest velocity achieved during the test was recorded as the PTS. When subjects were not able to complete the last stage, the PTS was calculated from the following equation (21): PTS=LCS + (TLIS/180 $\times$ speed increment $)$ where LCS 
is the velocity in the last complete stage performed by the subject, and TLIS is the time in seconds sustained by the subject in the last incomplete stage.

10-kilometer running time trial. Participants performed the T10-km on an outdoor 400-m track and were instructed to finish the race as quickly as possible, as if in a competitive event. Before the trial, the participants warmed up for $10 \mathrm{~min}$ at $12 \mathrm{~km} / \mathrm{h}$. They were instructed to maintain regular water consumption within $6 \mathrm{~h}$ of testing and water was provided ad libitum during the entire event. Verbal encouragement was provided during the entire event. Speed and heart rate were registered at each 100 $m$ via a global positioning system (GPS Forerunner ${ }^{\mathbb{R}} 405$, Garmin, USA) and the mean velocity of each section was calculated. Maximal heart rate was the highest value obtained at the end of the test. Ambient temperature and humidity values were provided by the Institute of Astronomy, Geophysics and Atmospheric Sciences of the University of São Paulo, São Paulo, SP, Brazil. The means $\pm S D$ values for temperature and humidity were $22.8 \pm 1.3^{\circ} \mathrm{C}$ and $61.0 \pm 4.2 \%$, respectively.

Calculation of energy system contributions. Energy system contributions during each stage of the IET were determined as previously described $(22,23)$. Briefly, the net aerobic energy system was estimated by subtracting $\dot{\mathrm{VO}}_{2}$ baseline from the $\dot{\mathrm{V}} \mathrm{O}_{2}$ exercise area integrated over time by the trapezoidal method. To estimate the glycolytic system contribution, a value of $1 \mathrm{mM}$ [La-]net was considered to be equivalent to $3 \mathrm{~mL} \mathrm{O} / \mathrm{kg}$ body mass (24). Because the ATP-PCr system is predominantly used to resynthesize of ATP during high-intensity (3-5 times the power output that elicits $\dot{\mathrm{V}} \mathrm{O}_{2 \text { max }}$ ), short duration exercises ( $\sim 10 \mathrm{~s})(25)$, and the contribution of alactic metabolism was not considered. The aerobic $\left(\mathrm{W}_{\mathrm{AER}}\right)$ and glycolytic $\left(W_{\text {GLYCOL }}\right)$ energy system contributions represented the sum of all stages in IET. The total metabolic demand ( $\mathrm{W}_{\text {TOTAL }}$ ) was the sum of both energy metabolism contributions. $W_{\mathrm{AER}}$ and $\mathrm{W}_{\mathrm{GLYCOL}}$ are also reported as a percentage of $\mathrm{W}_{\text {TOTAL. }}$ A caloric equivalent of $20.9 \mathrm{~kJ} / \mathrm{L} \mathrm{O}_{2}$ was used for the energy systems calculations.

\section{Statistical analyses}

The distribution of the data was analyzed using the Shapiro-Wilk test, and the results showed a normal Gaussian distribution. Data are reported as means \pm SD. Paired $t$-tests were used to compare the $\mathrm{W}_{\mathrm{AER}}$ and $\mathrm{W}_{\mathrm{GLYCOL}}$ contributions of each stage during the IET. Pearson's correlation coefficient was calculated to assess the relationship between the energy system contributions and physiological variables (PTS, RCP, and $\dot{\mathrm{V}}_{2 \max }$ ) with partial running speed sections (start: first $400 \mathrm{~m}$, middle: from 400 to $9600 \mathrm{~m}$, and finish: last $400 \mathrm{~m}$ ) and overall performance. The statistical power for the correlations was calculated as $1-\beta$, and is reported as a percentage (\%). The level of significance was set at $\alpha=0.05$. All statistical analyses were conducted using the SPSS statistical package (version 16.0, USA).

\section{Results}

\section{Energy system contributions during the incremental exercise test}

Table 1 shows the physiological and performance parameters measured during the IET, and the heart rate and section running speeds during the T10-km. Table 2 shows the energy system contributions reported as absolute and percentage values for each stage of the IET. The $W_{A E R}$ was significantly higher compared with $\mathrm{W}_{\mathrm{GLYCOL}}$ throughout the IET $(\mathrm{P}<0.05)$. The $\mathrm{W}_{\mathrm{AER}}$ increased continuously up to $223.3 \pm 30.0 \mathrm{~kJ}$, while $\mathrm{W}_{\mathrm{GLYCOL}}$ increased continuously up to $45.8 \pm 8.8 \mathrm{~kJ}$. When reported as a percentage, the $\mathrm{W}_{\mathrm{AER}}$ continuously decreased from $94.6 \pm 10.2 \%$ at $13 \mathrm{~km} / \mathrm{h}$ to $82.9 \pm 11.0 \%$ at $18 \mathrm{~km} / \mathrm{h}$, while the $W_{\mathrm{GLYCO}}$ continuously increased from $5.4 \pm 3.5$ to $17.1 \pm 3.3 \%$.

\section{Ten-kilometer running performance}

The $W_{\text {AER }}(r=-0.85 ; P=0.01), W_{\text {GLYCOL }}(r=-0.67$; $\mathrm{P}=0.01)$, and $\mathrm{W}_{\text {TOTAL }}(\mathrm{r}=-0.83 ; \mathrm{P}=0.01)$ estimated from the IET were significantly correlated with the T10-km time. The PTS ( $r=-0.78 ; P=0.01)$, RCP ( $r=-0.56 ; P=0.04)$, and $\dot{\mathrm{V}} \mathrm{O}_{2 \max }(\mathrm{r}=-0.67 ; \mathrm{P}=0.01)$ were also significantly correlated with the T10-km time. Table 3 shows the Pearson's correlation coefficient of the running speed in different sections of the T10-km with the energy system contribution and physiological variables. The $\mathrm{W}_{\mathrm{AER}}, \mathrm{W}_{\mathrm{GLYCOL}}$, and $\mathrm{W}_{\text {TOTAL }}$ were positively and significantly correlated with the running speed in the middle and final sections and with the mean speed in the T10-km. Similarly, PTS also correlated with the middle and final sections, and mean speed in the T10-km, while RCP correlated with the middle section and mean speed. However, $\mathrm{V}_{2 \max }$ did not correlate with any of the speed sections and none of the variables correlated with the start section (Table 3 ).

\section{Discussion}

The present study was conducted to determine the association between performance in a T10-km and energy system contributions estimated during an IET. Our results showed that $\mathrm{W}_{\mathrm{AER}}, \mathrm{W}_{\mathrm{GLYCOL}}$ and $\mathrm{W}_{\text {TOTAL }}$ were significantly correlated with the T10-km time. Additionally, $\mathrm{W}_{\mathrm{AER}}$, $\mathrm{W}_{\mathrm{GLYCOL}}$, and $\mathrm{W}_{\text {TOTAL }}$ were positively and significantly correlated with speed in the middle and final sections of the T10-km. These findings indicated that an estimation of aerobic and glycolytic metabolism during IET is an alternative variable to be considered for the evaluation of long-distance runners, with the additional advantage of being related to specific sections of a T10-km run.

Because the intensity of exercise progressively increases throughout the IET, the contribution of energy systems is altered to meet the increasing energy demand. Although most sport scientists and coaches believe that metabolic pathways have a transitional nature during the 
Table 1. Physiological and performance parameters measured during an incremental exercise test and heart rate and section running speeds during a $10-\mathrm{km}$ running time trial $(\mathrm{n}=13)$.

\begin{tabular}{|c|c|c|}
\hline & Means \pm SD & $\begin{array}{c}95 \% \\
\text { Confidence } \\
\text { interval }\end{array}$ \\
\hline $\mathrm{W}_{\mathrm{AER}}(\mathrm{kJ})$ & $973.3 \pm 284.8$ & 818.7-1127.9 \\
\hline $\mathrm{W}_{\mathrm{GLYCOL}}(\mathrm{kJ})$ & $98.9 \pm 47.1$ & $73.4-124.4$ \\
\hline $\mathrm{W}_{\text {TOTAL }}(\mathrm{kJ})$ & $1072.2 \pm 326.6$ & $894.8-1249.6$ \\
\hline $\mathrm{RCP}(\mathrm{km} / \mathrm{h})$ & $15.5 \pm 1.0$ & $15.0-16.0$ \\
\hline PTS $(\mathrm{km} / \mathrm{h})$ & $17.1 \pm 1.2$ & $16.5-17.7$ \\
\hline$\dot{\mathrm{V}} \mathrm{O}_{2 \max }\left(\mathrm{mL} \cdot \mathrm{kg}^{-1} \cdot \mathrm{min}^{-1}\right)$ & $53.8 \pm 5.4$ & $50.9-56.7$ \\
\hline T10-km time $(\mathrm{min})$ & $43.8 \pm 4.3$ & $41.5-46.1$ \\
\hline Heart rate $(\mathrm{bpm})$ & $180 \pm 8$ & $175-184$ \\
\hline Start (first $400 \mathrm{~m}, \mathrm{~km} / \mathrm{h}$ ) & $14.8 \pm 1.8$ & $13.8-15.7$ \\
\hline Middle (400-9600 m, km/h) & $13.8 \pm 1.3$ & $13.1-14.5$ \\
\hline End (last $400 \mathrm{~m}, \mathrm{~km} / \mathrm{h}$ ) & $13.9 \pm 2.0$ & $12.8-14.9$ \\
\hline Average $(10,000 \mathrm{~m}, \mathrm{~km} / \mathrm{h})$ & $13.8 \pm 1.3$ & $13.1-14.5$ \\
\hline
\end{tabular}

Data are reported as means $\pm S D$. $W_{\mathrm{AER}}$ : aerobic energy system contribution; $W_{\text {GLYCOL: }}$ glycolytic energy system contribution; $W_{\text {TOTAL }}$ : total metabolic demand; $\mathrm{RCP}$ : respiratory compensation point; PTS: peak treadmill speed; $\dot{\mathrm{VO}}_{2 \max }$ : maximal oxygen uptake; T10-km time: total time to complete $10-\mathrm{km}$ running time trial.

IET, only one study has quantified the profiles of aerobic and glycolytic metabolism during an IET (13). It was demonstrated that the aerobic contribution was predominant during all stages of the IET and that there was an increase in the glycolytic contribution at intensities equal to or above the anaerobic threshold. These results are in accordance with the data of the current study, because the $\mathrm{W}_{\mathrm{AER}}$ was significantly higher than $\mathrm{W}_{\mathrm{GLYCOL}}$ throughout the IET. Therefore, the results of the current study confirm the idea that aerobic metabolism is predominant throughout IET and that the glycolytic contribution becomes substantial, but not predominant, during the last stages of an IET (13).

Our results also showed that the correlation coefficient between T10-km time and $\mathrm{W}_{\text {TOTAL }}$ was higher than between the $T 10-\mathrm{km}$ time and the other variables traditionally related to endurance performance (i.e., PTS,
$\mathrm{RCP}$, and $\dot{\mathrm{VO}}_{2 \max }$ ). In addition, the $\mathrm{W}_{\mathrm{AER}}$ and $\mathrm{W}_{\mathrm{GLYCOL}}$ were also significantly correlated with the overall running performance during the T10-km. These correlations observed between energy system contributions during IET and T10-km might be associated with the energy profile of those undertaking long-distance events. Previous findings indicated a high relative aerobic contribution (96\%) during long-distance running, suggesting the importance of oxidative metabolism for overall running performance (26). Therefore, aerobic contribution might be related to endurance performance because of the high capacity (total amount of available energy) of aerobic metabolism to resynthesize ATP, so it can be recruited at high magnitudes over a long period of time (25). Furthermore, Duffield et al. (16) demonstrated that aerobic metabolism provided the major pathway for energy supply to runners of 1500 - and $3000-m$ track events, with the

Table 2. Energy system contributions reported as absolute and percentage values in each stage of an incremental exercise test ( $n=13)$.

\begin{tabular}{lcccccc}
\hline & \multicolumn{7}{c}{ Speed $(\mathrm{km} / \mathrm{h})$} \\
\cline { 2 - 7 } & 13 & 14 & 15 & 16 & 17 & 18 \\
\hline Aerobic (kJ) & $169.3 \pm 18.3^{*}$ & $178.6 \pm 21.2^{*}$ & $190.0 \pm 22.9^{*}$ & $199.2 \pm 21.7^{*}$ & $210.3 \pm 22.7^{*}$ & $223.3 \pm 30.0^{*}$ \\
Aerobic (\%) & $94.6 \pm 10.2^{*}$ & $94.0 \pm 11.2^{*}$ & $90.6 \pm 10.9^{*}$ & $88.1 \pm 9.6^{*}$ & $85.6 \pm 9.2^{*}$ & $82.9 \pm 11.1^{*}$ \\
Glycolytic (kJ) & $9.6 \pm 6.3$ & $11.3 \pm 8.6$ & $19.6 \pm 10.9$ & $26.8 \pm 10.9$ & $35.5 \pm 12.2$ & $45.8 \pm 8.8$ \\
Glycolytic (\%) & $5.4 \pm 3.5$ & $6.0 \pm 4.5$ & $9.4 \pm 5.2$ & $11.9 \pm 4.8$ & $14.4 \pm 5.0$ & $17.1 \pm 3.3$ \\
W & $178.9 \pm 24.6$ & $189.9 \pm 29.8$ & $209.6 \pm 33.8$ & $226.0 \pm 32.6$ & $245.8 \pm 34.9$ & $269.1 \pm 38.8$ \\
\hline
\end{tabular}

Data are reported as means $\pm \mathrm{SD}$. $\mathrm{W}_{\text {TOTAL }}$ : total metabolic demand. ${ }^{*} \mathrm{P}<0.05$, compared to glycolytic contribution (paired $t$-tests). 
Table 3. Correlation coefficients between energy system contribution, physiological variables, and section running speeds during the $10-\mathrm{km}$ running time trial.

\begin{tabular}{lcccccccc}
\hline & Start & Stat power & Middle & Stat power & End & Stat power & Average & Stat power \\
\hline $\mathrm{W}_{\text {AER }}(\mathrm{kJ})$ & 0.51 & 45.5 & $0.89^{*}$ & 99.6 & $0.83^{*}$ & 97.1 & $0.83^{*}$ & 97.1 \\
$\mathrm{~W}_{\mathrm{GLYCOL}}(\mathrm{kJ})$ & 0.32 & 19.2 & $0.76^{*}$ & 90.1 & $0.69^{*}$ & 79.1 & $0.68^{*}$ & 77.3 \\
$\mathrm{~W}_{\text {TOTAL }}(\mathrm{kJ})$ & 0.49 & 42.0 & $0.89^{*}$ & 99.6 & $0.82^{*}$ & 96.4 & $0.82^{*}$ & 96.4 \\
$\mathrm{RCP}(\mathrm{km} / \mathrm{h})$ & 0.34 & 21.3 & $0.61^{* *}$ & 64.1 & 0.54 & 50.8 & $0.82^{*}$ & 96.4 \\
$\mathrm{PTS}(\mathrm{km} / \mathrm{h})$ & 0.32 & 19.2 & $0.78^{*}$ & 92.6 & $0.76^{*}$ & 90.1 & $0.78^{*}$ & 92.6 \\
$\mathrm{VO}_{2 \text { max }}\left(\mathrm{mL} \cdot \mathrm{kg}^{-1} \cdot \mathrm{min}^{-1}\right)$ & 0.11 & 5.5 & 0.47 & 38.7 & 0.52 & 47.2 & 0.31 & 18.2 \\
\hline
\end{tabular}

Start: first $400 \mathrm{~m}$; middle: 400-9600 m; end: last $400 \mathrm{~m}$; average: 10,000 m. The statistical power (Stat power) for the correlations was calculated as $1-\beta$, and is reported as a percentage (\%). $W_{\text {AER }}$ : aerobic energy system contribution; $W_{G L Y C O L}$ : glycolytic energy system contribution; $W_{\text {TOTAL }}$ : total metabolic demand; RCP: respiratory compensation point; PTS: peak treadmill speed; $\dot{V}_{2 \text { max }}:$ maximal oxygen uptake; ${ }^{*} \mathrm{P}<0.01$; ${ }^{* *} \mathrm{P}<0.05$ (Pearson's correlation coefficient).

aerobic contribution increasing as the event distance increases. In turn, the high rate of energy production (power) of anaerobic metabolism can influence endurance performance and determine the ability of an athlete to accelerate in specific sections of a long distance race, for example a sprint at the end (27). Furthermore, Lazzer et al. (28) determined the effects of long-lasting endurance events on the energy cost of running and showed that a substantial increase in the cost of running during the competition caused a marked worsening of performance. Therefore, athletes with a high ability to resynthesize ATP aerobic and anaerobically during IET might also be able to maintain higher speeds during a running race.

In the current study, the contributions of aerobic and glycolytic metabolism determined during the IET were also significantly correlated with the middle and final sections of the T10-km. These findings are in agreement with previous studies showing changes in both aerobic and glycolytic metabolism in events performed with different pacing strategies $(10,17,29)$. Hettinga et al. (10) demonstrated that in $4000 \mathrm{~m}$ cycling time trials, aerobic contribution increased toward the end of the race, independent of strategy, but the power distribution during these races appeared to be regulated primarily by changes in anaerobic contribution. Santos et al. (29) reported that the time to complete a 4-km cycling time trial was negatively associated with the total anaerobic work expended ( $r=-0.77)$. Thus, it seems that because of the relationship with the aerobic and anaerobic contribution during a race, estimating the energy system contributions during IET to evaluate the endurance of athletes has an additional advantage in predicting the performance during specific sessions (i.e., middle and end phases) of long-distance events.

In relation to physiological variables, the middle section of the T10-km was correlated with PTS and RCP, while the final section was correlated with PTS only. Considering that the intensity of the end sprint seems to be dependent on anaerobic energy expenditure (10), the correlation of PTS with the final section could be expected, because it is also influenced by anaerobic characteristics (30). In turn, a possible advantage in attaining the RCP at higher intensities could be the achievement of higher speeds without the accumulation of metabolites related to muscle fatigue. RCP occurs in response to an initial decrease of blood $\mathrm{pH}$, which represents the beginning of failure of muscle buffering capacity (31). Foster et al. (32) suggested that athletes learn how to monitor values of muscle $\mathrm{pH}$ and adjust their pacing accordingly so that they ideally reach critically low values of $\mathrm{pH}$ near the end of a race. This could preserve the capacity of skeletal muscle to produce force during the middle section. Because the last part of a race might not be long enough for the establishment of acidosis, athletes could attain high speeds independently of muscle buffering capacity. This might explain the lack of correlation between RCP and running intensity during the final section.

In turn, $\dot{\mathrm{V}} \mathrm{O}_{2 \max }$ was not correlated with any speed sections in the T10-km. This result is in contrast with previous findings (33), but similar with results of another study conducted by Lima-Silva et al. (34) in which the athletes covered a similar distance during a running trial. Although $\dot{\mathrm{V}}_{2 \text { max }}$ is considered an important determinant of elite performance in competitive distance running (1), it may not be sufficiently sensitive to predict performance in specific sessions of a T10-km run. In particular, previous findings suggested that $\dot{\mathrm{V}}_{2 \max }$ might not be a good predictor of endurance performance in homogeneous groups (3). Despite the absence of studies including specific running speed sections, several studies have shown that other variables (i.e., PTS) besides $\dot{V}_{2 \max }$ were related to endurance performance $(3,35)$. Thus, at least for running speed sections, $\dot{\mathrm{V}}_{2 \max }$ might not be a good predictor of running pace in a T10-km.

It was interesting to observe that no correlation was obtained with the first $400 \mathrm{~m}$ of the T10-km. It was previously demonstrated that the time needed for the stabilization of physiological variables (e.g., oxygen uptake) that are important for this event was greater than 
the time required to complete this first section of the run (36). In this context, Bertuzzi et al. (33) demonstrated that in a $10-\mathrm{km}$ running time trial, only the rate of perceived exertion accounted for the variance of speed during the start phase. Therefore, the authors suggest that psychological factors may be more important during the early stages of a running race than physiological factors (33). This could explain the results found in the present study, because the first $400 \mathrm{~m}$ were not correlated with any measured physiological variable.

In conclusion, the results of the present study demonstrated a positive and significant correlation between $W_{A E R}$, $\mathrm{W}_{\text {GLYCOL }}$, and $\mathrm{W}_{\text {TOTAL }}$ with the running speed in the middle and final sections of a $10-\mathrm{km}$ running time trial. These findings showed that the assessment of energy system contributions during IET may be potentially useful as an alternative variable to evaluate endurance runners, and assess a runner's performance in specific parts of a long

\section{References}

1. Morgan DW, Baldini FD, Martin PE, Kohrt WM. Ten kilometer performance and predicted velocity at $\dot{\mathrm{V}}_{2 \max }$ among well-trained male runners. Med Sci Sports Exerc 1989; 21: 78-83, doi: 10.1249/00005768-198902000-00014.

2. Faude $\mathrm{O}$, Kindermann W, Meyer T. Lactate threshold concepts: how valid are they? Sports Med 2009; 39: 469-490, doi: 10.2165/00007256-200939060-00003.

3. Noakes TD, Myburgh $\mathrm{KH}$, Schall R. Peak treadmill running velocity during the $\mathrm{VO}_{2 \max }$ test predicts running performance. J Sports Sci 1990; 8: 35-45, doi: 10.1080/02640419008732129.

4. Bassett DR Jr, Howley ET. Limiting factors for maximum oxygen uptake and determinants of endurance performance. Med Sci Sports Exerc 2000; 32: 70-84, doi: 10.1097/00005768200001000-00012.

5. Saunders PU, Pyne DB, Telford RD, Hawley JA. Factors affecting running economy in trained distance runners. Sports Med 2004; 34: 465-485, doi: 10.2165/00007256200434070-00005.

6. Svedahl K, Maclntosh BR. Anaerobic threshold: the concept and methods of measurement. Can J Appl Physiol 2003; 28: 299-323.

7. Noakes TD. Implications of exercise testing for prediction of athletic performance: a contemporary perspective. Med Sci Sports Exerc 1988; 20: 319-330, doi: 10.1249/00005768198808000-00001.

8. Thiel C, Foster C, Banzer W, De Koning J. Pacing in Olympic track races: competitive tactics versus best performance strategy. J Sports Sci 2012; 30: 1107-1115, doi: 10.1080/ 02640414.2012 .701759$.

9. St Clair Gibson A, Lambert EV, Rauch LH, Tucker R, Baden $D A$, Foster $C$, et al. The role of information processing between the brain and peripheral physiological systems in pacing and perception of effort. Sports Med 2006; 36: 705-722, doi: 10.2165/00007256-200636080-00006.

10. Hettinga FJ, De Koning JJ, Broersen FT, Van Geffen P, Foster C. Pacing strategy and the occurrence of fatigue in 4000-m cycling time trials. Med Sci Sports Exerc 2006; 38: 1484-1491, doi: 10.1249/01.mss.0000228956.75344.91. distance race. From a practical standpoint, sports scientists and coaches could use these variables measured during an IET, particularly $\mathrm{W}_{\text {TOTAL, }}$ as an alternative method to diagnose the training status of endurance athletes. This might be especially relevant because the application of knowledge regarding energy system contributions involved in any athletic event is considered important for the correct administration and structuring of training regimes to achieve peak athletic performance (16).

\section{Acknowledgments}

The authors thank the athletes who participated in this research. This study was supported by FAPESP (\#2011/ 10742-9). M.V. Damasceno would like to acknowledge the support from FAPESP (\#2013/00371-9). R. Bertuzzi would like to acknowledge the financial support from CNPq (303233/2013-3).

11. Nummela AT, Paavolainen LM, Sharwood KA, Lambert MI, Noakes TD, Rusko HK. Neuromuscular factors determining $5 \mathrm{~km}$ running performance and running economy in welltrained athletes. Eur J Appl Physiol 2006; 97: 1-8.

12. Beneke R, Beyer T, Jachner C, Erasmus J, Hutler M. Energetics of karate kumite. Eur J Appl Physiol 2004; 92: 518-523.

13. Bertuzzi R, Nascimento EM, Urso RP, Damasceno M, Lima-Silva AE. Energy system contributions during incremental exercise test. J Sports Sci Med 2013; 12: 454-460.

14. Guidetti L, Emerenziani GP, Gallotta MC, Baldari C. Effect of warm up on energy cost and energy sources of a ballet dance exercise. Eur J Appl Physiol 2007; 99: 275-281.

15. Micklewright D, Alkhatib A, Beneke R. Mechanically versus electro-magnetically braked cycle ergometer: performance and energy cost of the Wingate Anaerobic Test. Eur J Appl Physiol 2006; 96: 748-751.

16. Duffield R, Dawson B, Goodman C. Energy system contribution to 1500- and 3000-metre track running. J Sports Sci 2005; 23: 993-1002, doi: 10.1080/02640410400021963.

17. Silva-Cavalcante MD, Correia-Oliveira CR, Santos RA, Lopes-Silva JP, Lima HM, Bertuzzi R, et al. Caffeine increases anaerobic work and restores cycling performance following a protocol designed to lower endogenous carbohydrate availability. PLoS One 2013; 8: e72025, doi: 10.1371/journal.pone.0072025.

18. Jones AM, Doust JH. A $1 \%$ treadmill grade most accurately reflects the energetic cost of outdoor running. J Sports Sci 1996; 14: 321-327, doi: 10.1080/02640419608727717.

19. Howley ET, Bassett DR Jr, Welch HG. Criteria for maximal oxygen uptake: review and commentary. Med Sci Sports Exerc 1995; 27: 1292-1301, doi: 10.1249/00005768-19950900000009.

20. Meyer T, Lucia A, Earnest CP, Kindermann W. A conceptual framework for performance diagnosis and training prescription from submaximal gas exchange parameters - theory and application. Int J Sports Med 2005; 26 (Suppl 1): S38-S48. 
21. Kuipers H, Rietjens G, Verstappen F, Schoenmakers H, Hofman G. Effects of stage duration in incremental running tests on physiological variables. Int J Sports Med 2003; 24: 486-491.

22. Bertuzzi RC, Franchini E, Kokubun E, Kiss MA. Energy system contributions in indoor rock climbing. Eur $J$ Appl Physiol 2007; 101: 293-300.

23. Bertuzzi RC, Franchini E, Ugrinowitsch C, Kokubun E, Lima-Silva AE, Pires FO, et al. Predicting MAOD using only a supramaximal exhaustive test. Int J Sports Med 2010; 31: 477-481.

24. di Prampero PE, Ferretti G. The energetics of anaerobic muscle metabolism: a reappraisal of older and recent concepts. Respir Physiol 1999; 118: 103-115, doi: 10.1016/ S0034-5687(99)00083-3.

25. Gastin PB. Energy system interaction and relative contribution during maximal exercise. Sports Med 2001; 31: 725-741, doi: 10.2165/00007256-200131100-00003.

26. Weyand P, Cureton K, Conley D, Sloniger M. Percentage anaerobic energy utilized during track running events. Med Sci Sports Exerc 1993; 25: S105, doi: 10.1249/00005768$199305001-00588$.

27. Fukuba Y, Whipp BJ. A metabolic limit on the ability to make up for lost time in endurance events. J Appl Physiol 1999; 87: 853-861.

28. Lazzer S, Salvadego D, Rejc E, Buglione A, Antonutto G, di Prampero PE. The energetics of ultra-endurance running. Eur J Appl Physiol 2012; 112: 1709-1715.

29. Santos RA, Kiss MA, Silva-Cavalcante MD, Correia-Oliveira CR, Bertuzzi R, Bishop DJ, et al. Caffeine alters anaerobic distribution and pacing during a 4000-m cycling time trial. PLoS One 2013; 8: e75399, doi: 10.1371/journal.pone. 0075399

30. Paavolainen L, Nummela A, Rusko H. Muscle power factors and $\mathrm{V}_{2 \text { max }}$ as determinants of horizontal and uphill running performance. Scand J Med Sci Sports 2000; 10: 286-291, doi: 10.1034/j.1600-0838.2000.010005286.x.

31. Meyer T, Faude O, Scharhag J, Urhausen A, Kindermann W. Is lactic acidosis a cause of exercise induced hyperventilation at the respiratory compensation point? Br J Sports Med 2004; 38: 622-625.

32. Foster C, Schrager M, Snyder AC, Thompson NN. Pacing strategy and athletic performance. Sports Med 1994; 17: 77-85, doi: 10.2165/00007256-199417020-00001.

33. Bertuzzi R, Lima-Silva AE, Pires FO, Damasceno MV, Bueno S, Pasqua LA, et al. Pacing strategy determinants during a $10-\mathrm{km}$ running time trial: contributions of perceived effort, physiological, and muscular parameters. J Strength Cond Res 2014; 28: 1688-1696.

34. Lima-Silva AE, Bertuzzi RC, Pires FO, Barros RV, Gagliardi JF, Hammond $\mathrm{J}$, et al. Effect of performance level on pacing strategy during a 10-km running race. Eur J Appl Physiol 2010; 108: 1045-1053.

35. Stratton E, O'Brien BJ, Harvey J, Blitvich J, McNicol AJ, Janissen D, et al. Treadmill velocity best predicts 5000-m run performance. Int J Sports Med 2009; 30: 40-45.

36. Xu F, Rhodes EC. Oxygen uptake kinetics during exercise. Sports Med 1999; 27: 313-327, doi: 10.2165/00007256199927050-00003. 